\title{
IMAGENS CRISTALIZADAS: a construção dos estereótipos sobre as favelas
}

\section{CRYSTALLIZED IMAGES: the construction of stereotypes on favelas}

\author{
ROCHA, Daniella Guedes ${ }^{1}$
}

\section{Resumo:}

Este artigo trata da construção por diferentes autores, entre eles a mídia, das representações das favelas como lugares perigosos, focos de criminalidade, que devem ser temidos - o que influencia o modo como também são representados os moradores desses espaços. O estudo discorre sobre as imagens construídas sobre a favela no Rio de Janeiro desde o seu surgimento, no fim do século XIX, que se cristalizaram em estigmas e estereótipos sobre este espaço, e apresenta uma análise de conteúdo de matérias atuais que aponta para a pluralização dos enquadramentos sobre as favelas na mídia.

Palavras-chave: Enquadramento; Imprensa; Favelas; Estereótipos.

\begin{abstract}
:
This article deals with the construction by different authors, among them, the media, of favelas representations as dangerous places, areas of crime, which must be feared - which influences the way in which the inhabitants of these spaces are also represented. The study deals with the images built on the favela in Rio de Janeiro since its inception, at the end of the 19th century, crystallized in stigma and stereotypes about this space, and presents a content analysis of current issues that points to the pluralization of the frameworks on the favelas in the media.
\end{abstract}

Keywords: Framework; Press; Favelas; Stereotypes.

\footnotetext{
${ }^{1}$ Doutora em História, Política e Bens Culturais no Centro de Pesquisa e Documentação de História Contemporânea do Brasil (CPDOC) da Fundação Getúlio Vargas e Mestra em Estudos Populacionais e Pesquisas Sociais (2010) pela Escola Nacional de Ciências Estatísticas (ENCE/IBGE), com graduação em Comunicação Social, habilitação em Jornalismo, pela Universidade do Estado do Rio de Janeiro (2006).
} 


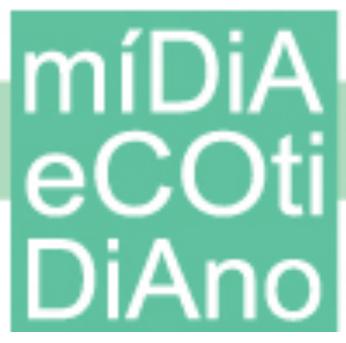

\section{Introdução}

A realidade, enquanto produção histórica, é construída por práticas sociais que tentam explicar "o mundo, os objetos que nele existem, os sujeitos que nele habitam" (COIMBRA, 2001, p.38). O jornalismo, como uma dessas práticas sociais, busca no conceito de enquadramento um modo de organização dos milhares de eventos que ocorrem a cada momento, e da infinidade de detalhes noticiáveis em cada um deles. Estes princípios ajudam os jornalistas a processarem as muitas informações a que têm acesso, reconhecendo o que é notícia e tratando os dados antes que eles sejam publicados. Ao trabalharem com seleção e omissão, ênfases e entonações, dentre diversas outras formas de tratamento do texto, os meios de comunicação de massa representam uma significativa força social na formulação e delimitação de ideologias (GITLIN, 1980, p. 9).

Porto (2002, p.76) afirma que o conceito de enquadramento corresponde a um segundo nível de efeitos da mídia, ao determinar não só sobre o que o público pensa, com o agendamento (agenda setting), mas também como o público pensa sobre determinados temas. $\mathrm{O}$ agendamento teria o poder de fazer com que as pessoas insiram ou excluam de seus conhecimentos aquilo que a mídia insere ou exclui de seu conteúdo - "a agenda da mídia termina por se constituir também na agenda individual e mesmo na agenda social" (HOHLFELDT, 1997, p. 44). Para Coimbra (2001, p. 40), os meios de massa indicam "quais fatos devemos ignorar, a que outros devemos estar atentos, sobre o que é necessário ter opinião e discutir; quais, em suma, são os assuntos importantes para as nossas vidas". Os acontecimentos que não se fizerem presentes nos meios de comunicação passam a não existir; não aconteceram. E neste processo, para Chomsky (1988, p.304), "na mídia, como em outras instituições, aqueles que não possuem os valores e perspectivas requeridos serão considerados irresponsáveis, ideológicos, e aberrações, e tenderão a ser deixados de lado". E quando lembrados, estes grupos são “desqualificados e menorizados" (COIMBRA, 2001, p.52), ou, ainda, apresentados como "inimigos internos do regime". Esta marginalização atinge "os segmentos mais pauperizados; todos aqueles que os 'mantenedores da ordem' consideram 'suspeitos' e que devem, portanto, ser evitados e, mesmo, eliminados" (idem, p.58). Consequentemente, é nas páginas policiais que normalmente são veiculadas notícias 


\section{míDiA

sobre as classes populares, nas quais estas aparecem como centrais, enquanto que em outras áreas do noticiário seu acesso é impossível ou secundário.

Já o conceito de framing foi forjado pelo sociólogo Erving Goffman (1986), que entendia os enquadramentos como princípios construídos socialmente que permitem às pessoas dar sentido às situações nas quais estão inseridas. Antes de ser usado no campo da Comunicação, o conceito serviu à Psicologia. Kahneman e Tversky (1984 e 1986) demonstraram como mudanças nas formulações de problemas causam variações nas preferências das pessoas; estas decidem de acordo com a forma pela qual as questões são enquadradas. A primeira aplicação relevante do conceito de enquadramento em estudos sobre a mídia foi no livro Making News, da socióloga Gaye Tuchman (1978), em que defendia que as notícias impõem um enquadramento que define e constrói a realidade. Tuchmam foi seguida, no campo da Comunicação, por autores como Todd Gitlin (1980), Daniel Hallin (1994) e Robert M.Entman (1994). Para Gitlin (1980, p.7), enquadramentos "são padrões persistentes de cognição, interpretação e apresentação, de seleção, ênfase e exclusão, através dos quais os manipuladores de símbolos cotidianamente organizam o discurso, tanto verbal quanto visual". Ainda segundo Gitlin (1980), este sistema de enquadramentos no qual a cobertura se apoia ajuda a formar representações do real, quando continuamente repetido. Estas representações se referem à seleção de determinadas versões do fato, dentre muitas outras, o que acaba por construir uma interpretação particular da realidade.

\footnotetext{
Enquadrar significa selecionar alguns aspectos de uma realidade percebida e fazê-los mais salientes em um texto comunicativo, de forma a promover uma definição particular do problema, uma interpretação causal, uma avaliação moral e/ou uma recomendação de tratamento para o item descrito (ENTMAN, 1994, p.294).
}

Neste contexto, espaços são estigmatizados como "perigosos" e certos grupos sociais, como "potenciais criminosos". Esta estigmatização pode produzir os chamados "subúrbios problemáticos", os territórios "estigmatizados como sendo locais perigosos e violentos por natureza". As subjetividades criadas em relação aos moradores dos espaços segregados passam a guiar não só as atitudes dos moradores das outras partes da cidade, mas também as atitudes do próprio grupo estigmatizado. O estigma criado pelos discursos 
é absorvido pelos membros deste grupo, e muitos deles acabam convencidos de sua própria inferioridade. Para Goffman (1982, p.15), a questão principal de se estigmatizar indivíduos consiste em que "acreditamos que alguém com um estigma não seja completamente humano. Com base nisso, faremos vários tipos de discriminação, através das quais efetivamente, e muitas vezes sem pensar, reduzimos suas chances de vida".

No caso das favelas do Rio de Janeiro, desde o começo do século XX foram criados, pela mídia, estereótipos sobre estes espaços e seus moradores, exacerbados a partir da década de 1980, quando passam a proporcionar "material para um produto midiático valioso sob a forma de medo ou estranheza" (ZALUAR \& ALVITO, 2006, p. 22). Ao focar o discurso na exacerbação da violência urbana, a mídia forma uma "sociedade que fica sabendo a quem temer, contra quem se precaver, os lugares a evitar, com quem não conviver" (MANSO, 2002). Este medo vendido pela mídia cria a diferenciação entre a ordem e a desordem, transmitindo ao leitor de classe média que ele é um cidadão diferenciado, que não se identifica com a barbárie em que os favelados estão inseridos. Os estereótipos influenciam ainda o modo como também são representados os moradores desses espaços. Os pobres, que são as maiores vítimas da violência, são também apontados como seus maiores agentes, sendo a pobreza ora determinante da vitimização, ora da ação violenta.

Este artigo parte de uma pesquisa anterior da autora (ROCHA, 2010), em que a construção destas imagens foi retomada através do conceito de enquadramento, encontrando categorias utilizadas em análise de conteúdo posterior. Os meios através dos quais os estudiosos identificam os enquadramentos contidos nos textos noticiosos podem ser variados, e o julgamento de que um enquadramento pode ou não estar presente geralmente é subjetivo (HALLIN, 1994, p.81). Neste caso, a identificação dos enquadramentos sobre a favela deu-se através de pesquisa histórica sobre como este espaço tem sido retratado desde o seu surgimento. As categorias de enquadramentos identificadas foram aplicadas posteriormente na análise de conteúdo de 50 matérias atuais. Esta metodologia foi utilizada de modo a permitir a reconstituição da construção dos estereótipos e estigmas sobre estes espaços e, em seguida, apresentar o que se considera um movimento recente no sentido de pluralizar estas representações. 


\section{míDiA \\ eco DiAno}

\section{O espaço a ser temido}

As favelas surgiram na cidade do Rio de Janeiro no final do século XIX (o ano de 1897 é dado como marco), e, desde então, vem sendo relacionada a diversas representações, algumas delas positivas, [muitas] outras negativas. As representações negativas, ao longo do tempo, criaram diversos estereótipos em relação às favelas e aos moradores das mesmas, notadamente como um lugar a ser evitado por ser o local por excelência da criminalidade, algo exacerbado a partir da década de 1980. Ainda no início do século XX, as descrições realizadas por escritores, jornalistas e reformadores sociais já carregavam consigo ideias estereotipadas sobre as favelas. Os morros da cidade eram vistos como locais perigosos e refúgios de criminosos, e, na imprensa e em documentos oficiais, surgia a associação entre o termo favela e a imagem de perigo e desordem. Ou seja, a favela é percebida como um problema praticamente no momento em que surge, a partir da ocupação do Morro da Favella (hoje Providência).

Esta primeira representação das favelas pode ser uma herança das representações dos cortiços e casas de cômodo, vinculadas a habitações das "classes perigosas". O cortiço carioca, "definido como um verdadeiro 'inferno social', era visto como antro de vagabundagem e do crime, além de lugar propício às epidemias", um espaço "propagador da doença e do vício" (VALLADARES, 2005, p.24). Pareceria então "natural a representação da favela retomar a ideia de doença, mal contagioso, patologia social a ser combatida" (idem, p.40). Assim, já no início do século XX, surge o enquadramento da favela como local da criminalidade, mesmo que dividindo espaço com um forte enquadramento higienista, em que estas áreas são vistas como um problema sanitário. A Revista Careta, de 04/12/1909, afirma que, “(...) apesar de possuir elementos honestos, a Favella é um antro de faccinoras e deve ser arrasado para decencia e hygiene da Capital Federal". Ao descrever os moradores da favela como facínoras, a imprensa estabelece um contato mecânico - mediado por forças externas ao grupo (MAIA \& KRAPP, 2005, p.36) - entre os favelados e os habitantes de outras partes da cidade que já se caracteriza pela visão do outro como um problema. O favelado é considerado classe perigosa simplesmente por representar o diferente no que diz respeito à ocupação do espaço urbano (CAMPOS, 2007, p.63). A construção do estigma do morador da favela como um 


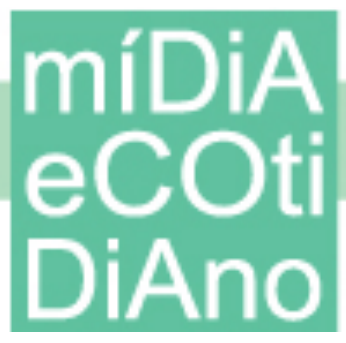

indivíduo à margem da sociedade teve influência ainda da lei vigente no começo do século, que classificava de vagabundo todo aquele que não tinha domicílio fixo, posição na qual os favelados se enquadravam.

Surgia ainda a visão dicotômica que perdura até os dias atuais, contrapondo a favela, miserável e imunda, à cidade em si. Em 1908, Olavo Bilac escreve a crônica Fora da vida, em que retrata uma lavadeira do morro da Conceição (próximo à atual Praça Mauá) que não descia para a cidade há 33 anos. Enquanto a cidade é representada pelo moderno, com moradores que trabalham e vivem, o morro é representado pelo atraso, sendo habitado por criaturas que, na opinião do cronista, não vivem - o que justifica o título da crônica. Valladares (2005, p.36) ressalta que este outro mundo, longe da cidade, era alcançado apenas através da "ponte construída pelo repórter ou cronista, levando o leitor até o alto do morro que ele, membro da classe média ou da elite, não ousava subir". Ressalta-se, neste ponto, que favela, nos jornais da década de 1910, era nome próprio, escrito sempre com F maiúsculo, e caracterizava somente o morro da Favela. A partir dos anos 1920, entretanto, acompanhando a difusão espacial deste tipo de moradia, o termo se substantivou e passou a se aplicar a todos os outros aglomerados de barracos existentes na cidade.

Para Zaluar e Alvito (2006), a maioria dos autores que escreveram nesta época (entre 1908 e 1923) sobre as favelas cariocas inseriu em seus discursos o conceito de dualidade presente na crônica de Bilac. O jornalista Benjamin Costallat descrevia a favela "como uma cidade dentro da cidade", enquanto o sambista Orestes Barbosa afirmava que havia "duas cidades no Rio". Uma destas cidades, segundo o escritor Lima Barreto, seria europeia, enquanto a outra, indígena. Este enquadramento dicotômico, usado para descrever uma cidade dividida, também esteve presente na obra de João do Rio, que, ao falar da favela, se sente "na roça, no sertão, longe da cidade", e lança mão de pares opositores como dentro/fora, alto/baixo, centro/periferia, avanço tecnológico/atraso. As favelas, quando enquadradas de um modo dicotômico, eram vistas como um espaço externo à cidade, que seria o território de exercício da cidadania. Nessa lógica, o reconhecimento da cidadania acaba sendo relativizado de acordo com o local de moradia do indivíduo, o que faz com que, desde o começo do século $\mathrm{XX}$, a cobertura dada aos moradores do asfalto e aos da favela seja diferenciada. 
O primeiro censo das favelas do Rio de Janeiro, de 1948, apesar de ter sido uma tentativa de melhor conhecer este universo, sustenta a visão preconceituosa contra os moradores que ali habitavam. Segundo o texto que precede as estatísticas, os "pretos e pardos" prevaleciam nas favelas por serem "hereditariamente atrasados, desprovidos de ambição e mal ajustados às exigências sociais modernas" (citado em ZALUAR \& ALVITO, 2006, p.13). O favelado, neste sentido, é visto como "o 'outro', distinto do morador civilizado da primeira metrópole que o Brasil teve" (idem, p.8). Por outro lado, em 1950, o Recenseamento Geral do Instituto Brasileiro de Geografia e Estatística (IBGE) registra pela primeira vez os mesmos dados para a favela e o conjunto da cidade. Nas conclusões, o autor rompe com diversas representações usuais da época em relação à favela, ressaltando a heterogeneidade existente entre elas e afastando-se de um olhar preconceituoso sobre seus moradores. "Não se trata, pois, de uma população composta de marginais, mas de aglomerados humanos integrados regularmente na vida social" (GUIMARÃES, 1953, p.261). A maior proporção de negros e mestiços entre os favelados devia-se a que estes compõem os grupos de baixa renda, com menor acesso a empregos mais qualificados e mais bem remunerados.

As décadas de 1940 e 1950 foram marcadas pela construção do enquadramento da favela como o espaço de ausências e carências. A precariedade de infraestrutura existente nas favelas levou ao surgimento das imagens que fizeram destes espaços o "lugar da carência, da falta", o lugar por excelência da desordem (ZALUAR \& ALVITO, 2006, p.8). É, nas palavras de Oliveira e Marcier (2006, p.73), o “espaço do Não”, quando a favela se afirma a partir de suas características físicas, dos aspectos visíveis, “emergindo como o espaço da habitação precária e improvisada, do predomínio do rústico sobre o durável, da ausência de arruamento, da escassez de serviços públicos”. Para Silva e Barbosa (2005, p.24), é este o eixo principal de representação da favela: a noção da ausência. O espaço é definido pelo que não tem: "um lugar sem infraestrutura urbana água, luz, esgoto, coleta de lixo -, sem arruamento, sem ordem, sem lei, sem moral e globalmente miserável. Ou seja, o caos". Alvito (2006) afirma, contrapondo a esta noção de carência, que um de seus entrevistados em Acari via na favela uma obra de décadas de trabalho, um espaço construído pelos próprios moradores, com suas mãos e seu suor. Naquela miséria aparente, há uma comunidade que se caracteriza "pelo cuidadoso 
planejamento no uso de um limitado espaço para fins de moradia, e pelas técnicas criativas de construção em encostas que os urbanistas consideram demasiado íngremes para edificação" (PERLMAN, 1977, p.27). E se as casas inicialmente eram feitas de materiais baratos e rústicos, o motivo era o medo das remoções. "A elite nunca soube que os moradores viviam com tanta humildade porque temiam as remoções. De que valia gastar um dinheiro sacrificado, se podíamos ser despejados a qualquer momento?", questiona o eletricista Feliciano da Silva Pinto, de 70 anos, morador do Cantagalo (apud RAMALHO, 2002).

Os debates sobre a favela nos anos 1960 sofreram a influência do relatório elaborado pela Sociedade para a Análise Gráfica e Mecanográfica Aplicada aos Complexos Sociais (SAGMACS) sobre as favelas cariocas, coordenado pelo sociólogo José Arthur Rios, orientado pelo Padre Louis-Joseph Lebret e publicado no suplemento de um jornal de grande circulação, O Estado de S.Paulo. A conclusão da pesquisa, realizada entre 1957 e 1959, era de que os habitantes não constituíam um mundo à parte, eram "pobres como outros pobres", e ainda vítimas do clientelismo político. Em suas pesquisas na década de 1970, Janice Perlman também questiona alguns mitos desenvolvidos sobre os moradores das favelas. A autora constata que a vida familiar na favela era relativamente estável, segundo qualquer padrão, e que os moradores tinham aspirações semelhantes à classe média; se não as alcançavam, é porque não lhes era dada a oportunidade. Os Mitos da Marginalidade descritos pela autora indicam como tipo ideal um indivíduo que vive em meio à imundície e à miséria, marcado pela desorganização social evidenciada na dissolução da família, na anomia, na falta de confiança e cooperação, no crime e na violência; profundamente pessimista e fatalista; parasita e sanguessuga dos recursos públicos, e desinteressado em política; preguiçoso, pouco contribuindo para a economia com seu trabalho ou consumo (PERLMAN, 1977, p.165). Este enquadramento trata a favela como aglomerações patológicas - a população favelada é formada por vagabundos, desempregados, ladrões, bêbados e prostitutas, que vivem em condições subumanas, sem serviços urbanos básicos, e constituem um dreno dos recursos públicos, não contribuindo para o bem geral. Estas definições estão tão arraigadas que muitos favelados estão convencidos de sua própria incapacidade. 
Na época do estudo, Perlman (1977) constatou que três quartos dos trabalhadores recebiam menos de um salário mínimo. E, como eram muitos, havia sempre uma quantidade enorme de trabalhadores à disposição do mercado, o que permitia a manutenção dos baixos salários e do não cumprimento das leis trabalhistas. Não eram economicamente marginais, quer como sanguessugas da economia, quer como um grupo que não dá valor ao trabalho nem ao seu aperfeiçoamento pessoal. No entanto, constantemente eram excluídos dos frutos da economia, ao serem relegados aos piores postos, com os piores salários. Portanto, os favelados não eram marginais, mas estavam integrados de uma forma prejudicial a eles. A maioria usava constantemente e intensivamente as instituições urbanas e os serviços que a cidade oferecia, não estando isolados na favela. Esta integração não impedia, porém, que os favelados fossem considerados "bodes expiatórios para uma vasta gama de problemas sociais", a "fonte de todas as formas de aberração, perversidade e criminalidade" (PERLMAN, 1977: 304), e, sem meios de defenderem sua própria imagem, permitiam à sociedade repurificar sua autoimagem.

Nos anos 1980, a visão sobre as favelas sofre novo revés. Com a chegada do tráfico de cocaína, a favela passa a ser representada como "covil de bandidos, zona franca do crime, habitat natural das "classes perigosas"” (ZALUAR \& ALVITO, 2006, p.15), um enquadramento focado na favela como local da criminalidade. Relatos e reportagens que mostravam a violência, o tráfico e a criminalidade nas favelas e em torno delas passaram a ocupar as páginas dos jornais. Valladares $(2005$, p.20) ressalta que "a associação, quase sistemática, entre pobreza e criminalidade violenta fez da favela sinônimo de espaço fora da lei, onde bandidos e policiais estão constantemente em luta". A violência ligada ao tráfico de drogas aparece, então, como um "novo divisor de águas, reatualizando a velha oposição entre a parte civilizada da cidade e a barbárie" (SANTOS, 2001, p.3). Com o avanço das organizações criminosas, a imprensa acaba por popularizar os chefes dos comandos entre os favelados e a população em geral. Mas a escolha de um único bandido como símbolo da criminalidade impedia uma análise mais aprofundada do fenômeno, o que contraria o interesse público. Em relação aos moradores, estes poderiam ser considerados vítimas ou cúmplices do tráfico, permitindo a presença do mesmo nas 


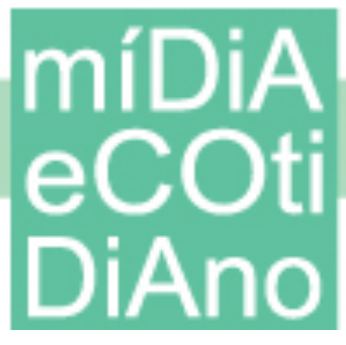

favelas. Ainda hoje, quando há manifestações, moradores são vistos como cúmplices, sem levar em conta o medo e a submissão dos que vivem sob o jugo do tráfico.

No começo da década de 1990, os arrastões nas praias da Zona Sul e as chacinas de Candelária e Vigário Geral são decisivos para a "acomodação da imagem da cidade partida como definidora da experiência urbana no Rio de Janeiro, cristalizada" com a publicação do livro Cidade Partida, de Zuenir Ventura, em 1994 (SANTOS, 2001, p. 93). No dia 21 de outubro de 1992, O Dia afirma que o que motivou os arrastões foi um conflito entre "gangues" da favela Nova Holanda e de Vigário Geral ${ }^{2}$. Um dos participantes do arrastão de domingo teria confirmado esta afirmação, dizendo, no entanto, que a insatisfação deles "era com os playboys da Zona Sul e contra essas pessoas que, quando veem a gente, vão escondendo a bolsa”. Na madrugada de 23 de julho de 1993, sete menores que dormiam sob a sacada da Igreja da Candelária, no Centro do Rio, foram assassinados. O motivo teria sido o apedrejamento de um carro da Polícia Militar no dia anterior, após a detenção de um menor que estava cheirando cola no local. Um mês depois, a cidade assistia a outra chacina. Quatro policiais foram assassinados em 28 de agosto na Praça Catolé da Rocha, em Vigário Geral. No dia seguinte, um grupo armado invadiu a favela e matou 21 pessoas. "PMs são acusados de nova chacina - Vingança teria motivado massacre de 21 favelados em Vigário Geral", estampa a capa da edição de 31 de agosto do jornal O Globo, com a foto, abaixo da manchete, dos corpos das vítimas perfilados. Nenhum dos mortos tinha antecedentes criminais. Um dia após o crime, os moradores, revoltados, "fecham ruas, apedrejam carros e PMs, que dão tiros para o alto". As ruas próximas à comunidade se transformaram em uma "praça de guerra".

Na década de 1990, o debate em torno das favelas passa a ter como eixo principal o desafio de integrá-las à cidade. Com a melhoria da infraestrutura das casas e da favela como um todo, as representações se deslocam, pouco a pouco, da noção de ausência. $\mathrm{O}$ Plano Diretor da Cidade, sancionado em 1992, decreta que as favelas passarão a integrar o processo de planejamento da cidade, constando nos mapas, cadastros, planos, projetos e legislação municipais, e assegura a presença dos moradores em suas comunidades.

\footnotetext{
2 “Conflito entre favelas começou arrastão de domingo nas praias”, O Dia, 21/10/1992, p. 8.
} 
Apesar desta ação política no papel, a favela vê sua representação como o espaço da criminalidade maximizada. Os confrontos ocorridos naqueles espaços passam a ser chamados de "guerra" pela mídia. "Morro Dona Marta, a guerra de cada dia", estampa o jornal $O$ Dia de 18 de outubro de 1992. Anos mais tarde, o jornal $O$ Globo passa a usar o termo “A Guerra do Rio" para descrever episódios violentos na cidade. Em abril de 2004, em um episódio chamado de "A Guerra da Rocinha", cinco pessoas foram assassinadas durante a tentativa de ocupação da comunidade por um grupo rival. Este termo passa a ser usado em repetidas coberturas pelo mesmo jornal, inclusive nos confrontos ocorridos no Complexo do Alemão em 2007 e em 2010. Uma das consequências de se tratar os conflitos urbanos como "guerra" é que, ao enfatizar quase exclusivamente as ações policiais na cobertura dos espaços populares, a mídia valoriza as ações bélicas para o problema da segurança. Como explica João Paulo Charleuaux, assessor de comunicação do Comitê Internacional da Cruz Vermelha, quando você diz que existe uma guerra, "criase a noção de território inimigo, de que o espaço onde o outro está não faz parte do seu território, e deve ser atacado ou ocupado. O outro passa a ser visto como inimigo, alguém que deve ser eliminado" (apud RAMOS \& PAIVA, 2007:57).

\section{Uma curta aproximação capaz de mudanças}

Este histórico das representações das favelas desde o seu surgimento permitiu à autora a identificação de categorias de enquadramentos: dicotômico, higienista, estético, favela como o espaço do "não", favela como o espaço da cultura popular, favela como espaço do trabalhador, favela como ameaça ao meio ambiente, favela como espaço da pobreza, favela como o espaço da criminalidade. Neste artigo, estas categorias foram aplicadas às 50 últimas matérias publicadas com a palavra-chave "Favela" encontradas em um site de busca em 14 de setembro de 2017, com o objetivo de identificar os enquadramentos presentes no texto. O propósito era investigar o que a autora considera uma aproximação ocorrida entre imprensa e favela na última década, mais precisamente desde 2008, quando o Governo do Estado lança uma nova política na área de segurança pública, com a instalação da primeira Unidade de Polícia Pacificadora (UPP) no Morro Santa Marta. A proposta consistia em uma polícia de proximidade, pautada no diálogo 
com as comunidades, em conjunto com projetos educacionais, culturais, esportivos e de inserção profissional. Em nove anos, o número de UPPs instaladas chegou a 38. Um ano antes do início da instalação das UPPs, houve o anúncio de vultosos recursos do Programa de Aceleração do Crescimento (PAC) para três grandes complexos de favelas do Rio de Janeiro - Complexo do Alemão, Complexo de Manguinhos e Rocinha -, no chamado PAC Favelas, gerido pelo Governo do Estado. Tratava-se de grandes obras de infraestrutura, de melhoria da locomoção e de construção de unidades habitacionais. Esta presença do Estado nas favelas cariocas devido ao PAC e às UPPs levou jornalistas de volta aos morros, gerando reportagens a partir destes lugares que apontavam as suas principais necessidades e também os aspectos positivos do cotidiano dos moradores.

As festas na laje, a precariedade dos serviços públicos, os bailes, as competições de dança e de esportes, e até mesmo brincadeiras de rua passaram a ser exibidos pela chamada grande mídia. Foram "descobertos" a escola de música do Santa Marta, a bela vista que se tem do alto do Morro da Fazendinha, no Complexo do Alemão, o Ano Novo no Morro da Babilônia e Chapéu Mangueira. Exemplos concretos podem ser encontrados em "Comunidades pacificadas no Rio precisam de outras mudanças" (https://globoplay.globo.com/v/3032920/), de 20/12/2013, do RJTV, mostrando o problema do saneamento básico naqueles espaços, e "Pacificação de favelas devolve ao Rio alguns de seus melhores cartões-postais" (http://veja.abril.com.br/brasil/pacificacaode-favelas-devolve-ao-rio-alguns-de-seus-melhores-cartoes-postais/), da Revista Veja, de 17/07/2011. A favela, por um momento, deixou de ser o espaço a ser temido; ao contrário, eram incentivadas as idas aos bares e às festas promovidas em locais com belíssimas vistas, como nas reportagens "De visita ao Rio? Conheça bares, festas e pontos turísticos das favelas" (http://g1.globo.com/rio-de-janeiro/noticia/2014/07/de-visita-aorio-conheca-bares-festas-e-pontos-turisticos-das-favelas.html), do Portal G1, de 13/07/2014, e "No Chapéu Mangueira, bar ganha prêmio e clientes 'do asfalto"” (http://g1.globo.com/economia/pme/noticia/2011/07/no-chapeu-mangueira-bar-ganhapremio-e-clientes-do-asfalto.html), também do Portal G1, de 12/07/2011.

Em 2001, ao ser lançado, o site Viva Favela (www.vivafavela.com.br), da ONG Viva Rio, já tinha como missão uma cobertura menos estigmatizante das favelas, afastando-se da visão voltada para aqueles espaços somente sob o prisma da violência. 
Em vez de isolar ou neutralizar estes espaços, o site estimulava propostas voltadas para integrá-los de uma forma harmônica à cidade. A favela, retratada pelos seus próprios moradores, os chamados correspondentes comunitários, emergia como um lugar de manifestações culturais únicas, experiências inovadoras, mesmo que precário em infraestrutura e equipamentos sociais. Seus moradores eram retratados como pessoas empreendedoras, lutadoras, necessitadas, ou apenas, como pessoas, sem estigmas atrelados. Nas matérias que focavam a criminalidade, os jovens mortos nas favelas eram identificados e suas famílias tinham voz. Após as UPPs, esse também passou a ser o tom das matérias nos grandes veículos. As fontes se diversificaram, deixando de ser apenas o boletim da ocorrência policial. E por estarem mais próximos dos moradores, os jornalistas passaram a mostrar os efeitos da violência sobre aquela população: o número de escolas fechadas, as crianças que precisam se proteger em meio a um tiroteio, a mudança na rotina dos trabalhadores, a espera dos mesmos para voltar para as suas casas nos dias mais violentos - como em "Tiroteios fecham escolas do Rio em mais da metade dos dias de aula de agosto" (http://cbn.globoradio.globo.com/editorias/policia/ 2015/09/02/TIROTEIOS-FECHAM-ESCOLAS-DO-RIO-EM-MAIS-DA-METADEDOS-DIAS-DE-AULA-DE-AGOSTO.htm), da Rádio CBN, de 02/09/2015, e “Assaltos e tiros levam pânico a trabalhador na volta pra casa" (http://odia.ig.com.br/noticia/rio-dejaneiro/2014-10-23/assaltos-e-tiros-levam-panico-a-trabalhador-na-volta-paracasa.html), do jornal O Dia, de 23/10/2014.

Nos últimos anos, houve um recrudescimento da violência no Rio de Janeiro, que não poupou áreas "pacificadas" da cidade e provocou novamente um afastamento dos jornalistas das favelas. A hipótese aqui investigada, no entanto, é de que o cenário atual da volta da violência levou à redução de matérias sobre outros aspectos que não seja a violência, predominando o enquadramento da favela como o espaço da criminalidade, mas não eliminou de vez dos noticiários pautas positivas sobre estes espaços. Na análise, foram encontradas 26 matérias com a favela sendo enquadrada como espaço da criminalidade, 15 matérias com enquadramento da favela como espaço do trabalhador ou do empreendedorismo, 05 matérias em que a favela é retratada como espaço do "não" o espaço da carência, da ausência de serviços públicos -, 01 matéria com o enquadramento do espaço da cultura popular - de produções culturais próprias e 


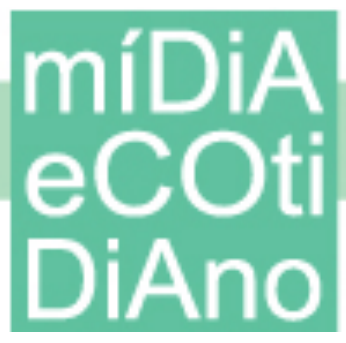

enriquecedoras - e 04 delas em que não foi possível detectar um enquadramento dominante.

As matérias sobre criminalidade enfocam, principalmente, operações policiais nas favelas, como a megaoperação em diversas comunidades do Rio de Janeiro que acontecia no dia 14 de setembro. Seis dias antes, o noticiário foi dominado por matérias sobre a apreensão de uma metralhadora do "Rambo", que era de brinquedo, como foi descoberto depois. A maioria das matérias retrata o resultado da violência: "Inocentes ficam na linha de tiro na Favela do Jacarezinho", O Globo, de 21/08; "Duas pessoas morrem em confrontos na favela do Jacarezinho, no Rio", Folha de S.Paulo, 20/08; "Rapaz é morto durante ação da PM para coibir baile funk em favela da Zona Norte de SP”, Globo.com, 30/08; e apenas uma discute a questão de violência de forma mais ampla, com uso de estatísticas - "Favelas têm taxa de homicídios por tiros três vezes maior do que as demais áreas do Rio", Jornal Extra, 21/08. Nas notícias com enquadramento de espaço da criminalidade, os moradores poderiam ser retratados ora como vítimas da violência ora como cúmplices do tráfico, permitindo a presença do mesmo nas favelas. Estudos anteriores (ROCHA, 2010) revelam que era comum esta segunda representação dos moradores, criminalizando-os. Exemplificando, no dia 17 de agosto de 1987, a Rocinha "desceu". Os moradores da comunidade fizeram uma manifestação na Autoestrada Lagoa-Barra para exigir, segundo o jornal $O G l o b o$, a libertação do "traficante e assassino" Denis Leandro da Silva. Cerca de 500 moradores fecharam a via, que se transformou em um "campo de batalha", sempre de acordo com o jornal. A presidente da associação de moradores fazia pessoalmente a defesa do traficante, "negociando" com os policiais.

A aproximação dos repórteres com as favelas, ocorrida na última década, no entanto, alterou sobremaneira esta representação dos moradores. Em uma análise detalhada sobre a ocupação do Complexo do Alemão em 2007, a autora (ROCHA, 2010) demonstra como os moradores daquele conjunto de favelas foram considerados as principais vítimas dos confrontos pela cobertura do jornal O Globo, em enquadramentos construídos pelo jornal ao enfatizar os relatos do cotidiano de medo nas comunidades, o

\footnotetext{
3 “Protesto na Rocinha vira corpo-a-corpo com a PM", O Globo, 18/08/1987, p. 14.
} 
alto número de feridos entre os moradores, a opressão mantida pelo tráfico e as dificuldades provocadas pela suspensão dos serviços básicos. E ao mostrar sua apreensão em meio aos confrontos, O Globo não ignorou a população do Complexo do Alemão, dando voz aos moradores. Entre as 50 matérias aqui citadas, a notícia "Vídeo de adolescente interrompido por tiros em favela no Rio viraliza: 'Triste, mas comum'”, do Jornal Extra, de 29/08/17, mostra a apreensão de uma adolescente que tentava realizar o primeiro vídeo para seu próprio canal no YouTube.

\begin{abstract}
Ao lado de uma amiga, ela contava, diante da câmera, um caso que viveu na escola e, de início, tomou apenas um pequeno susto ao ouvir disparos isolados. Ela não parou a gravação por causa disso, mas, pouco depois, é possível ouvir uma intensa troca de tiros, o que fez com que as meninas se levantassem às pressas. A gravação viralizou e deu à jovem a ideia de fundar um canal sobre a realidade das favelas.
\end{abstract}

As consequências da violência no cotidiano dos moradores se fazem presentes nas matérias atuais, enquadrando-os como as principais vítimas da criminalidade. E muitas das vezes estes impactos chegam pelo olhar dos moradores, quando enviam fotos e vídeos para os grandes veículos mostrando as marcas da violência dentro da favela, um fenômeno possibilitado em grande parte pela profusão de câmeras em telefones celulares. A Rede Globo não precisa mais enviar uma equipe à Rocinha após um tiroteio crítico para mostrar as consequências nas vielas da favela - vídeos enviados para a redação mostravam, na edição de 20 de setembro de 2017 do telejornal RJTV, as paredes cravadas por tiros, a igreja atingida, um poste de madeira quase rachando, uma moto queimada; consequências de um confronto entre duas facções rivais. Como colaboradores, os moradores mostram de fato como são afetados pela criminalidade.

Cinco das 26 matérias que enquadram a favela como espaço do crime dizem respeito a representações em outros contextos. Três delas citavam a violência em uma favela ficcional, da novela "Força do Querer", no horário nobre da Rede Globo, em que o núcleo favelado consistia basicamente em mostrar a rotina do tráfico e os confrontos com a Polícia Militar. Outras duas matérias tratavam da representação feita por alunos do Colégio Pedro II em uma exposição de trabalhos, em que um dos temas era "Um Dia na Favela". Segundo o Portal R7, na matéria "Alunos simulam 'bancada de drogas' em 
evento escolar e provocam polêmica", de 12/09, a representação da favela se deu com a simulação de uma feira de drogas no pátio da escola, com embalagens imitando tabletes de maconha e sacos de cocaína, e estudantes empunhando réplicas de armas. Era essa a imagem principal que os alunos possuíam dos espaços favelados.

As representações negativas sobre as favelas encontram contraponto nos enquadramentos que buscam mostrar outros aspectos destes espaços que não sejam só a violência, a criminalidade, o tráfico de drogas e suas consequências para os moradores, que ainda sofrem com velhos estereótipos e preconceitos. E, na busca dessa representação mais positiva, são as histórias de superação destes mesmos moradores que ganham destaque, seja como resultado de um esforço individual ou de uma ação coletiva.

Das 50 matérias aqui analisadas, 15 possuem como enquadramento o espaço do trabalhador ou do empreendedorismo. Das ações individuais, destacam-se as matérias sobre gêmeas da favela paulista do Jardim Peri que trabalham com moda e autoestima da mulher negra - "Com quase nada, essas gêmeas viraram ícones de moda da favela e de todo o Brasil”, Huffington Post Brazil, 16/08 -, sobre André Luiz Souza, que nasceu na periferia de Belo Horizonte e atualmente lidera uma equipe do Google, na Califórnia "Ele cresceu numa favela mineira, virou doutor nos EUA e agora é pesquisador do Google”, Época Negócios, 08/09 - , e sobre o campeão mundial de surfe Mineirinho, em relato sobre sua infância pobre - "Das favelas para as ondas, Mineirinho relembra infância difícil: 'Minha mãe colocou fogo na casa comigo dentro'”, ESPN.com.br, 13/09. Entre as ações coletivas, duas delas ganharam destaque no período: o lançamento de um movimento para colocar os jovens moradores das favelas no centro do debate sobre a política de drogas - "Jovens de favelas lançam movimento e cartilha sobre política de drogas", EBC, 02/09, e "Sou da favela, quero ser parte do debate sobre a guerra às drogas", EL PAÍS Brasil, 12/09 - e o lançamento do partido Frente Favela Brasil, registrado em 30 de agosto no Tribunal Superior Eleitoral pelo criador da Central Única de Favelas (CUFA), Celso Athayde - "Queremos o preto e o favelado no centro do processo decisório", Carta Capital, 12/09, e "Reage, favela", O Globo, 31/08. Embora as matérias com enquadramento voltado ao empreendedorismo representem $30 \%$ do total publicado no período, contra $52 \%$ das que relatam a criminalidade nas favelas, percebese uma tentativa de pluralização das pautas sobre estes espaços, de modo que o tema sobre 


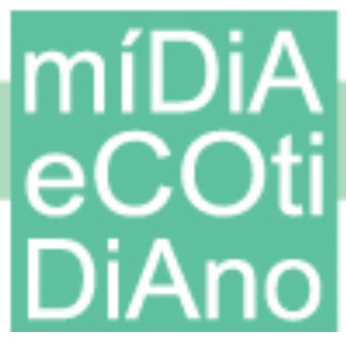

violência não seja o único, apesar de dominante. Retratados há mais de um século como marginais - à margem da sociedade e da cidade -, os moradores das favelas passam a se ver no centro de algumas pautas, seja como colaboradores dos veículos, como personagens de histórias positivas ou como principais vítimas da violência, que não os atinge somente, e sim toda a cidade.

\section{Considerações finais}

Se a imprensa ainda não abandonou a predominância do enquadramento da favela como local da criminalidade, os preconceitos e discriminações decorrentes (logicamente, em parte) destes enquadramentos também não foram abandonados. Uma pesquisa do Instituto Data Popular divulgada em fevereiro de 2015 indica que 69\% dos entrevistados do asfalto sentem medo ao passar diante de uma favela, e 51\% afirmaram que as primeiras palavras que vêm à mente quando ouvem sobre favela são droga e violência. Ou seja, uma clara associação deste território com a criminalidade. Quanto à relação com os favelados, $47 \%$ dos moradores do asfalto nunca contratariam, para trabalhar dentro de suas casas, uma pessoa que morasse em favela ${ }^{4}$. Apesar de o empreendedorismo nas favelas não parar de crescer e da ascensão dos moradores à classe $\mathrm{C}$, este tipo de visão, segundo o Instituto, constituiria uma barreira para que os moradores de favelas superem as dificuldades da precariedade de Estado nestes lugares.

A maioria dos jornalistas ouvidos em estudo de 2007 do Centro de Estudos de Segurança e Cidadania (CESeC), da Universidade Cândido Mendes' admitiu que seus veículos têm responsabilidade na representação das favelas como espaços exclusivos de violência. A população destas comunidades raramente conta com uma cobertura de questões não relacionadas com tráfico de drogas e criminalidade. Consequentemente, no imaginário coletivo, a favela continua a representar perigo, reproduzindo imagens que vêm sendo cristalizadas desde o começo do século XX. Gitlin (1980) argumenta que, geralmente, os editores e os repórteres são provenientes da classe média alta, tendendo a difundir as ideias compartilhadas pela sua classe. As fontes usadas tendem a ser as

\footnotetext{
${ }^{4}$ Disponível em http://agenciabrasil.ebc.com.br/geral/noticia/2015-02/moradores-do-asfalto-tem-visaopreconceituosa-em-relacao-favelas
} 
mesmas, e oficiais, o que "alija pontos de vista importantes do debate", e os meios de comunicação costumam depender de um número restrito de comentaristas fixos, sendo "pouco propensos a buscar opiniões novas e controversas" (KELLNER, 2001:274). Em seus estudos, Porto (2002) conclui que quando a notícia adota uma forma restrita, com um único enquadramento, um número maior de pessoas interpreta o fato relatado de acordo com este enquadramento dominante. A restrição do número de enquadramentos pode reduzir a possibilidade de os cidadãos elaborarem suas próprias opiniões a partir da comparação dos diferentes aspectos e perspectivas do fato.

Por outro lado, quando expostos a segmentos e opiniões plurais, os indivíduos têm acesso a várias interpretações e podem desenvolver um senso crítico sobre o assunto. A Internet e os novos aparatos tecnológicos permitem a novos atores veicular informações com pontos de vista distintos, em novos canais de diálogo, mesmo com alcance limitado. As transformações ocorridas nos últimos anos, dentre as quais se encontra a aproximação entre imprensa e favela ocorrida há quase uma década, possibilitaram o início da construção de uma cobertura mais plural sobre as favelas, retratando o amplo espectro de experiências vividas por seus moradores. Coberturas que ampliam as representações da favela e daqueles que ali vivem, abrindo caminhos para que suas chances de vida não continuem a ser reduzidas devido a estereótipos criados e mantidos há mais de cem anos.

\section{Referências}

ALVITO, Marcos. Um bicho-de-sete-cabeças. In: ZALUAR, Alba., ALVITO, Marcos. Um século de favela. Rio de Janeiro: Editora FGV, 2006.

CAMPOS, Audrelino. Do quilombo à favela: A produção do "espaço criminalizado" no Rio de Janeiro. Rio de Janeiro: Bertrand Brasil, 2007.

CHOMSKY, N.; HERMAN, E.S. Manufactoring Consent. Londres: Pantheon Books, 1988.

COIMBRA, Cecília. Operação Rio - O mito das classes perigosas: um estudo sobre a violência urbana, a mídia impressa e os discursos de segurança pública. Niterói: Oficina do Autor, 2001.

ENTMAN, R. Framing: Toward clarification of a fractured paradigm. In: LEVY, M.; GUREVITCH, M. (ed.). Defining Media Studies: reflections on the future of the field. New York: Oxford University Press, 1994.

GITLIN, Todd. The whole world is watching. Mass media in the making \& unmaking of the new left. Berkeley: University of California Press, 1980

GOFFMAN, Ervin. Estigma: notas sobre a manipulação da identidade deteriorada. Rio de Janeiro: Zahar Editores, 1982.

GUIMARÃES, A.P. As favelas do Distrito Federal. Revista Brasileira de Estatística, Rio de Janeiro, v.14, n.55, p.250-278, jul/set. 1953. 
HALLIN, D.C. We keep America on the top of the world. Television journalism and the public sphere. Routledge, 1994.

HOHLFELDT, A. Os estudos sobre a hipótese de agendamento. Revista FAMECOS, Porto Alegre, $\mathrm{n}^{\circ}$ 7, novembro/1997.

MAIA, João; KRAPP, Juliana. Comunicação e comunidade: Novas perspectivas das sociabilidades urbanas. In: FREITAS, Ricardo Ferreira; NACIF, Rafael. Destinos da cidade: comunicação, arte e cultura. Rio de Janeiro: EdUERJ, 2005.

OLIVEIRA, Jane Souto, MARCIER, Maria Hortense. A palavra é: favela. In: ZALUAR, Alba, ALVITO, Marcos. Um século de favela. Rio de Janeiro: Editora FGV, 2006.

MANSO, Bruno Paes. Ação e discurso - sugestão para o debate da violência. In OLIVEIRA, Nilson Vieira (org.). Insegurança pública: reflexões sobre a criminalidade e a violência urbana. São Paulo: Nova Alexandria, 2002.

PERLMAN, Janice. O mito da marginalidade: favelas e política no Rio de Janeiro. Rio de Janeiro: Paz e Terra, 1977.

PORTO, Mauro. Enquadramentos da mídia e política. In: Anpocs, 2002.

RAMALHO, Cristiane. Favela é... Publicado em 08/01/2002. Disponível em http://novo.vivafavela.com.br/publique. Acessado em 17/06/2009.

RAMOS, Silvia; PAIVA, Anabela. Mídia e violência: tendências na cobertura da criminalidade e segurança no Brasil. Rio de Janeiro: Iuperj, 2007.

ROCHA, D.G. "Da Batalha à Guerra do Rio: uma abordagem espaço-temporal da representação das favelas na imprensa carioca". Dissertação de Mestrado. Escola Nacional de Ciências Estatísticas (ENCE/IBGE). Rio de Janeiro, 2010.

SANTOS, Mariana Cavalcanti Rocha. Demolição, Batalha e Paz: favelas em manchetes. Dissertação (mestrado). Rio de Janeiro: UFRJ/ECO, 2001.

SILVA, Jailson de Souza; BARBOSA, Jorge Luiz. Favela: alegria e dor na cidade. Rio de Janeiro: Editora Senac Rio, 2005.

VALLADARES, Licia Prado. A invenção da favela. Do mito de origem à favela.com. Rio de Janeiro: Editora FGV, 2005.

ZALUAR, Alba, ALVITO, Marcos. Um século de favela. Rio de Janeiro: Editora FGV, 2006. 